\title{
A Study Regarding the Mechanical Properties of a Hybrid Matrix with Various Volume Proportions of Dammar
}

\author{
DUMITRU BOLCU ${ }^{1}$, MARIUS MARINEL STANESCU ${ }^{1 *}$, ION CIUCA $^{2}$, \\ COSMIN MIHAI MIRITOIU ${ }^{1}$, ALIN DINITA ${ }^{3}$, ALEXANDRU BOLCU $^{1}$ \\ ${ }^{1}$ Faculty of Mechanics, University of Craiova, 165 Calea Bucuresti, 200620, Craiova, Romania \\ ${ }^{2}$ Faculty of Engineering and Materials Science, Politehnica University of Bucharest, 313 Splaiul Independentei, 060042, \\ Bucharest, Romania \\ ${ }^{3}$ Petrolium-Gas University, Faculty of Mechanical and Electrical Engineering, 39 Bucuresti, 100680, Ploiesti, Romania
}

\begin{abstract}
This paper studies the influence of the volume proportion between components on the mechanical behaviour of a hybrid resin obtained by combining the natural resin Dammar and epoxy resin. We analyse three sets of hybrid resin samples, in which we used a Dammar volume proportion of $60 \%, 70 \%$, and $80 \%$ respectively and epoxy resin (employed together with its associated reinforcement in order to generate a quick process of polymerization). Following the tensile test we found the characteristic curves, the tensile strength and the elongation at break for each of the three types of resins. We also looked into the vibration damping properties of bars made of this resin. We experimentally determined the frequency and the damping coefficient of the first particular vibration mode for one bar taken out of each set of resins, with one end fixed and the other free. On the basis of the results, we calculated the loss coefficient for each type of resin.
\end{abstract}

Keywords: hybrid resin, mechanical behaviour, vibration damping properties

\section{Introduction}

Composite materials made from various matrix-reinforcing combinations are increasingly researched (from the point of view of mechanical and chemical behaviour) and based on these researches are used in various fields of activity. Thus, we can mention two recent papers.

In paper [1] are investigated the mechanical properties of the tail rotor blade of the IAR 330 helicopter (in the case in which the structural core is made from polyurethane foam).

A finite element model that is able to predict the shear elastic modulus of a double-layered composite material based on the elastic characteristics of its constituents was created in paper [2].

However, the composite materials based on raw renewable materials from agriculture and biomass, are increasingly utilized because they significantly compensate for the use of fossil fuels and decrease the greenhouse emissions in comparison to petrol-based conventional materials. Most composite materials studied so far have focused on natural fibres as reinforcing materials in combinations with thermoplastic matrices (polypropylene, polyethylene and vinyl polychloride), or thermorigid matrices (phenolic, epoxy and polyester resins) [3]. Including natural fibers into polymers poses several challenges, such as excessive absorption of water and low thermal properties, which must be overcome so as to produce materials having properties comparable to conventional composite materials.

Using synthetic resins has the disadvantage of a processing limit due to their high tack when melted, a phenomenon that occurs during the injection moulding. Thus, the final product is hard to be recycled. This disadvantage can be eliminated by using thermorigid biological matrices, based on vegetable oil resins, since the latter are biodegradable and there is no need of a polymerization process [4-5]. Bio-resins are resins derived from a biological source, so, they can be biodegradable or compostable, and therefore they can be decomposed after use. Sandarac, copal and Dammar are among the most used natural resins. Natural resins are insoluble in water but are slightly soluble in oil, alcohol

*email: mamas1967@gmail.com 
and, partially, petrol. They form, together with certain organic solvents, solutions used as covering varnishes. Turpentine, rosin, mastic are products resulted from coniferous resin distillation.

One shortcoming of natural lacquers is that they cannot form thick resins (for example, [6] and [7]). A solution for eliminating this shortcoming would be the use of a hybrid resin, obtained by combining several components, with at least one of them being organic and at least another one synthetic. We have to mention that the majority of the attempts to obtain such resins have taken place in the lacquer industry [6-8]. Hybrid resins are an environment-friendly alternative compared to the synthetic resins. Larger investigations about hybridization (in fibers and/or matrices), are available in [9] and [10]. The studies made on these resins focused more on their chemical composition and properties, presented in $[11,12]$, and less on their mechanical properties.

A particular case is Dammar, a resin obtained from trees of the Dipterocarpaceae family, from India and East Asia. Detailed studies on its structure and chemical composition have been carried out by [13] and [14]. Most frequently, until now, the Dammar films have been used as varnish to protect paintings [15]. Also, Dammar has also been used in order to obtain certain ecological binders, made of silicon and Dammar, with improved properties, which are shown in [16]. There, the optimal composition of this type of binders was determined, ensuring the best properties for impact stress, hardness, traction and adherence [17] analyses the way in which Dammar addition contributed to improving the rigidity, the modulus of elasticity and the hardness of modified silicon [18] looks into the mechanical features (tensile strength, percentage elongation and Young's modulus), the water vapour transmission characteristics and the characteristics of humidity absorption in Dammar films that contain and that do not contain softening agents.

The question how to obtain environment-friendly composite materials has been recurrent lately. The main challenge in this respect has consisted in obtaining hybrid matrices, made by mixing a natural resin (with a predominant volume proportion) and a synthetic resin (used in order to initiate the polymerization process). Natural fibers and fabrics (cotton, flax, silk, hemp, so on and so forth) have been prevailingly used as reinforcing materials. Dammar-based hybrid resins have been used recently with a view to obtaining composite materials, reinforced by natural fibers. Hybrid resins can be obtained by combing Dammar with an epoxy resin, as well as composite materials made of those resins by reinforcement with hemp, cotton, flax, straw and cattail. The influence of the epoxy resin volume proportion on the mechanical behaviour of the studied bio-resins and composite materials is important.

In this paper, we study certain mechanical properties of hybrid resins with a Dammar volume proportion of $60 \%, 70 \%$, and $80 \%$ respectively.

\section{Materials and methods}

The natural resin Dammar, by dilution with turpentine, is used for varnish protection. The resulting composition, if stored in sealed containers, remains in a liquid state and has the disadvantage of a long process of resin hardening, even though it is applied in thin layers. We removed this shortcoming by adding a synthetic resin and its associated reinforcement, so as to generate quick activation points of the polymerization process. Consequently, the new type of resin, obtained by mixing Dammar, turpentine, and an epoxy resin with its associated reinforcement, is a hybrid resin.

The first step consisted in casting hybrid resin plates, where we used a Dammar volume proportion of 60,70 , and $80 \%$ respectively. The difference up to $100 \%$ consisted of epoxy resin of the Resoltech 1050 type, together with its associated reinforcement of the Resoltech 1055 type. To increase the tack, necessary for the manufacturing process, we added a $10 \%$ proportion of Dammar powder to the obtained mixtures. The casting temperature was $20-23^{\circ} \mathrm{C} .10$ days after the casting, from the resulting plates, we produced sets of 10 samples each, with a length of $250 \mathrm{~mm}$ and a width of $25 \mathrm{~mm}$.

The samples underwent a tensile test, which was carried out according to the [19] provisions. We used the LRX Plus testing machine from LLOYD Instruments with the following specifications:

- force range: $2.5 \mathrm{kN}$; 
- travel: 1 to $735 \mathrm{~mm}$;

- crosshead speed: 0.1 to $500 \mathrm{~mm} / \mathrm{min}$;

- analysis software: NEXYGEN.

The elements obtained from this trial were: the characteristic curve, tensile strength $R_{m}[M P a]$, percentage elongation after fracture $A[\%]$ and elasticity modulus $E\left[\mathrm{~N} / \mathrm{mm}^{2}\right]$.

The following measuring instruments were used for the study of vibrations:

- SPIDER 8 data acquisition system, connected via USB to a notebook;

- the data acquisition set was made by means of the CATMAN EASY software, which linked the two entities;

- NEXUS 2692-A-0I4 conditioning amplifier, connected to SPIDER 8;

- $0.04 \mathrm{Pc} / \mathrm{ms}$ accelerometer, connected to the conditioning amplifier.

The frequency range was set from 0 to $2.400 \mathrm{~Hz}$ in SPIDER 8. To exclude the errors brought up by the experimental system, we performed a Butterworth "High Pass" filtering of each measurement, at a $3 \mathrm{~Hz}$ frequency.

\section{Result and discussions}

Henceforward, by representative sample of a given set we understand the sample with the average values of the studied mechanical properties.

On the basis of the tensile test we determined the characteristic curves, shown in figures $1-3$, for one representative sample of each of the three sets with a Dammar volume proportion of $60 \%, 70 \%$ and $80 \%$ respectively.
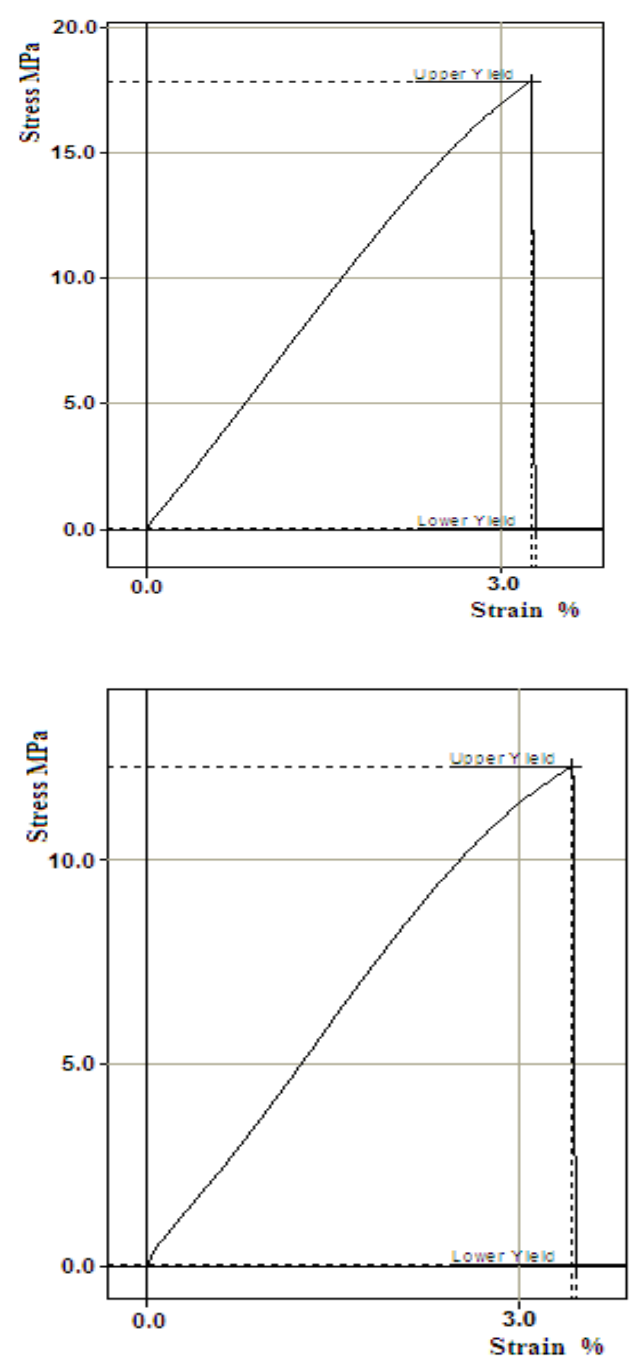

Figure 1. The characteristic curve for a representative sample of the $60 \%$ Dammar set
Figure 2. The characteristic curve for a representative sample of the $70 \%$ Dammar set 


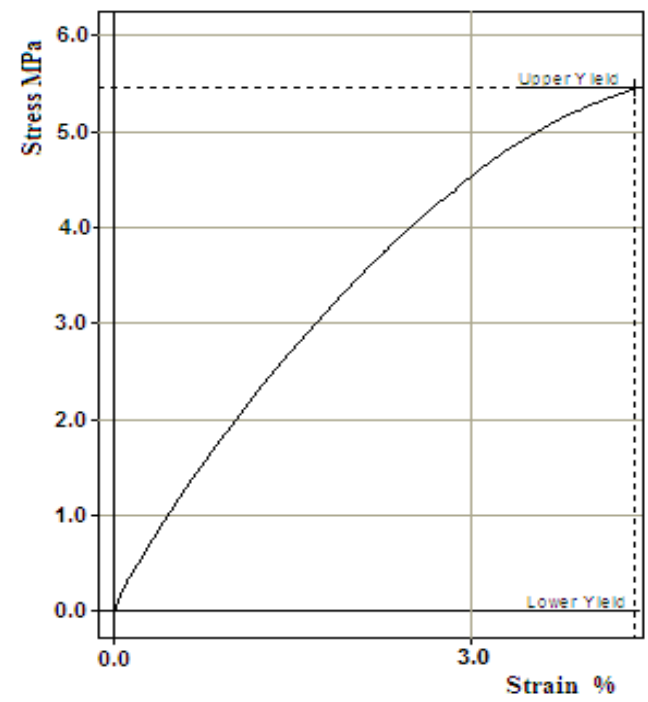

Figure 3. The characteristic curve for a representative sample of the $80 \%$

Dammar set

The trial results, based on the tensile test, for the hybrid resin sample sets are shown in Table 1.

Table 1. The value limits of the elastic modulus, tensile strength and elongation at break for the dammar-based hybrid resin samples

\begin{tabular}{|c|c|c|c|}
\hline $\begin{array}{c}\text { Dammar percentage in hybrid } \\
\text { resin }\end{array}$ & $\begin{array}{c}\text { Modulus of elasticity } \\
E[\mathrm{MPa}]\end{array}$ & $\begin{array}{c}\text { Tensile strength } \\
R_{m}[\mathrm{MPa}]\end{array}$ & $\begin{array}{c}\text { Elongation at break } \\
A[\%]\end{array}$ \\
\hline $60 \%$ & $920-1040$ & $17.3-18.4$ & $2.97-3.45$ \\
\hline $70 \%$ & $660-780$ & $12.5-13.6$ & $3.42-3.79$ \\
\hline $80 \%$ & $310-390$ & $5.3-5.8$ & $4.10-4.52$ \\
\hline
\end{tabular}

The accuracy of the theories used for the study of transversal vibrations in bars made of composite materials depends on the deformation hypotheses, taken into consideration for the construction of mathematical models. The main hypotheses underlying the main study models are:

- a movement, similar to that of simple bending;

- the movement component which is cause by the shearing deformation may vary in the section, depending on various laws (paraboloid, sinusoidal, hyperbolic or exponential);

- the transversal movement may be a function only on the longitudinal variable of the bar;

- a one-dimensional constitutive equation is used;

- the bars are submitted to external transversal charges only;

- there are no supplementary props during deformation.

These hypotheses do not consider the energy losses. In reality, due to internal friction and interaction with the air, all vibrations are damped. The presence of energy dissipation mechanisms is currently accepted in all the models used for simulating mechanical vibrations in mechanical systems. Many articles analyse various aspects and mechanisms of this phenomenon and its influence on the vibration behaviour of different composite materials (see for example [20-27]).

Regardless of the energy dissipation mechanism, in case of damping, the free bar vibrations are in the form of:

$$
w(x, t)=\sum_{n} W_{n}(x) e^{-\mu_{n} t} \sin \left(\sqrt{\omega_{n}^{2}-\mu_{n}^{2}} t+\varphi_{n}\right),
$$

where $\omega_{n}$ the specific pulsation, $\mu_{n}$ is the damping coefficient for the n vibration mode while $W_{n}(x)$ are the particular functions and depend on the limit conditions of the bar.

We determined the damping coefficient and the particular frequency of the first particular mode of vibration for the samples of the three types of resin. The studied samples were fixed at one end and the measurement was taken at the free end. The free lengths of the samples were $120 \mathrm{~mm}, 140 \mathrm{~mm}, 160$ $\mathrm{mm}$ and $180 \mathrm{~mm}$. 
The figures 4-6 show vibration recordings (the particular frequency and the damping coefficient) of one sample of each of the three sets with a Dammar volume proportion of $60 \%, 70 \%$ and $80 \%$ for the $120 \mathrm{~mm}$ free length. These lengths were chosen because the highest frequencies that are obtained in all three sets of samples obtained.

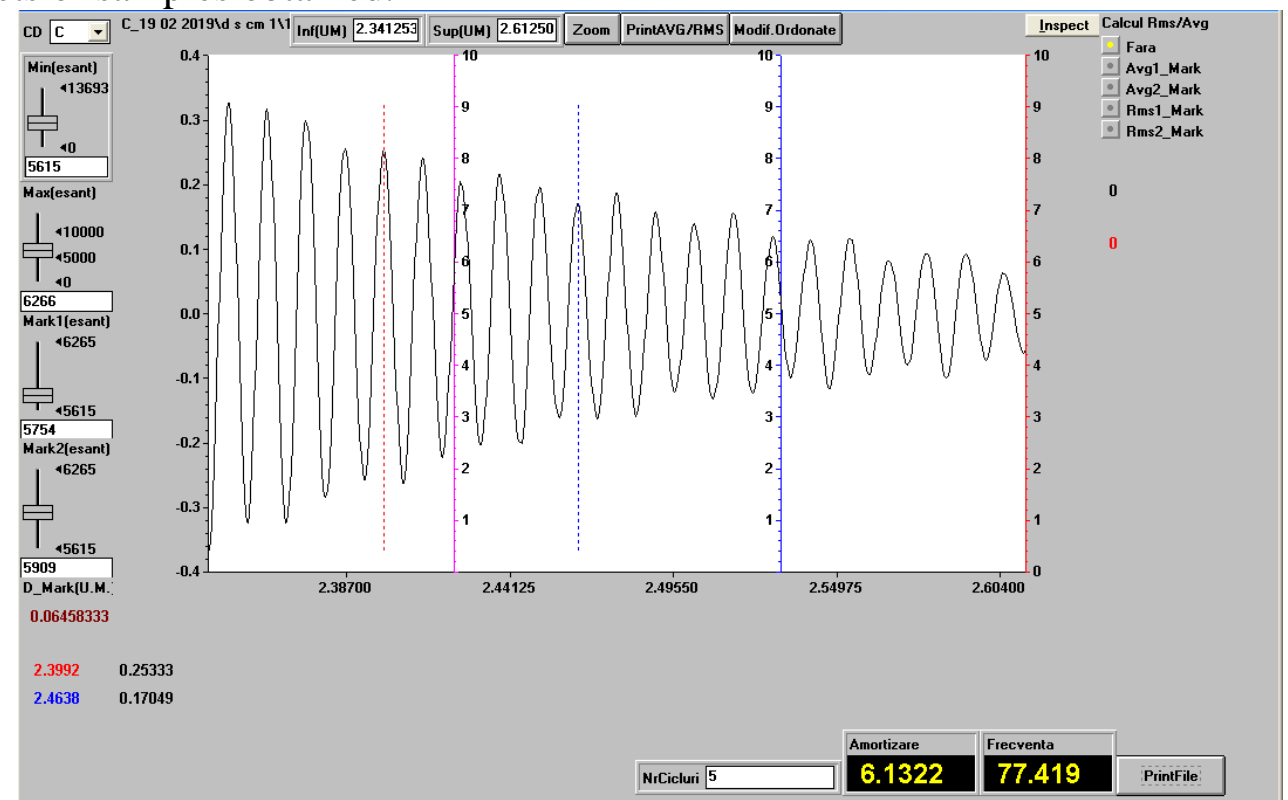

Figure 4. The vibration recording (particular frequency and damping coefficient) of a sample with $60 \%$ Dammar volume proportion, for the $120 \mathrm{~mm}$ free length

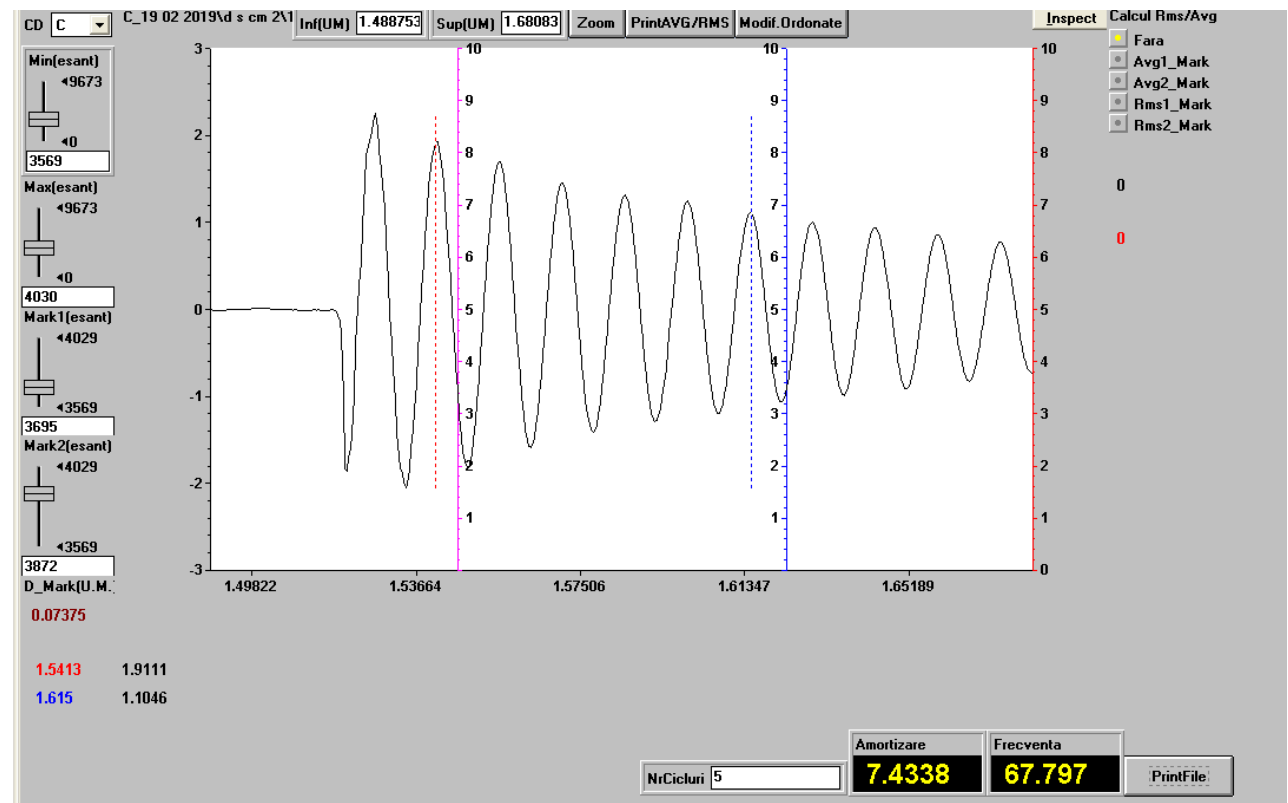

Figure 5. The vibration recording (particular frequency and damping coefficient) of a sample with $70 \%$ Dammar volume proportion, for the $120 \mathrm{~mm}$ free length 


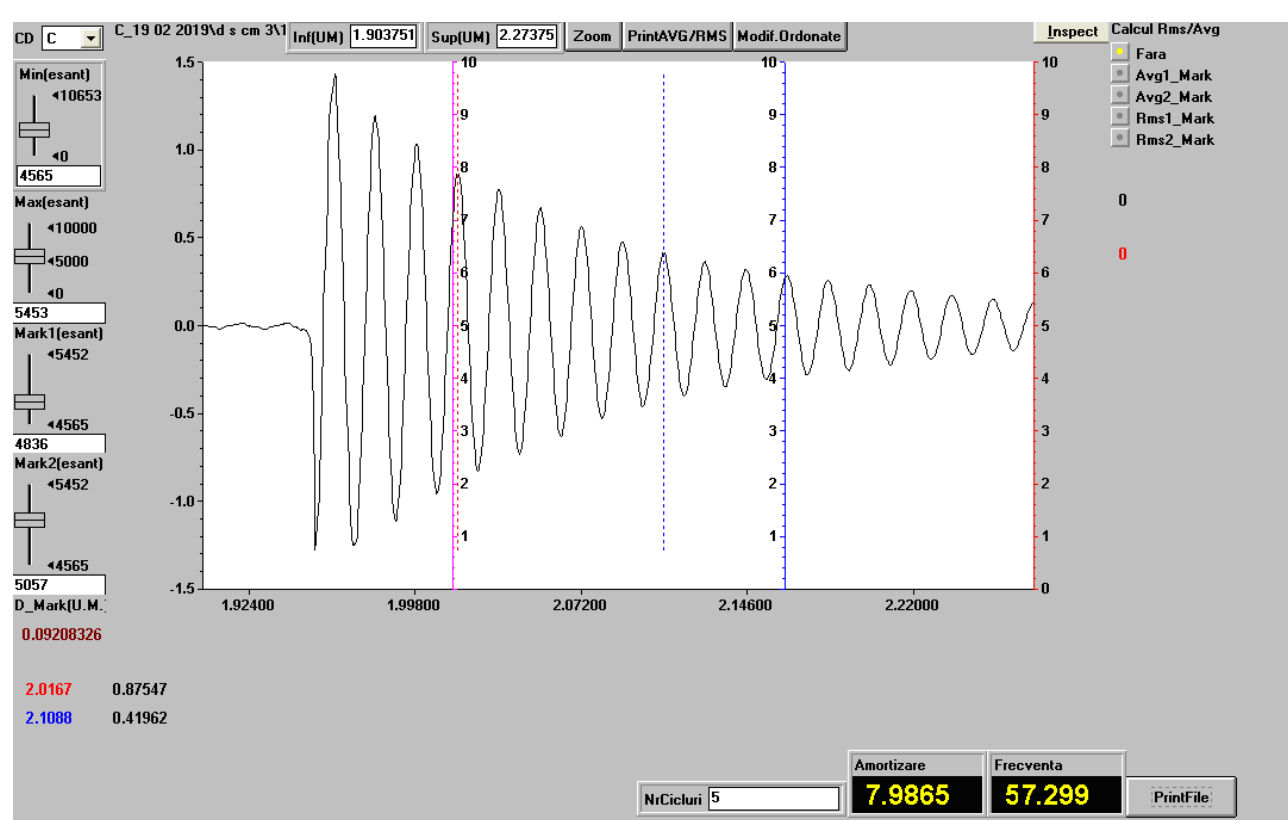

Figure 6. The vibration recording (particular frequency and damping coefficient) of a sample with $80 \%$ Dammar volume proportion, for the $120 \mathrm{~mm}$ free length

Table 2 shows the values of the damping coefficients and particular frequencies, calculated as the arithmetic mean of three consecutive measurements for the samples of the three resin sets (with a Dammar volume proportion of $60 \%, 70 \%$ and $80 \%$ respectively).

Table 2. The values of the damping coefficients and particular frequencies, calculated as the arithmetic mean of three consecutive measurements for the samples of the three resin sets obtained

\begin{tabular}{|c|c|c|c|c|c|c|}
\hline $\begin{array}{c}\text { Dammar Volume } \\
\text { proportion }\end{array}$ & \multicolumn{2}{|c|}{$60 \%$} & \multicolumn{3}{c|}{$80 \%$} \\
\cline { 2 - 7 } & $\begin{array}{c}\text { Damping } \\
\text { coefficient } \\
{\left[\mathrm{s}^{-1}\right]}\end{array}$ & Frequency & $\begin{array}{c}\text { Damping } \\
\text { coefficient } \\
{\left[\mathrm{s}^{-1}\right]}\end{array}$ & $\begin{array}{c}\text { Frequency } \\
{[\mathrm{Hz}]}\end{array}$ & $\begin{array}{c}\text { Damping } \\
\text { coefficient } \\
{\left[\mathrm{s}^{-1}\right]}\end{array}$ & $\begin{array}{c}\text { Frequency } \\
{[\mathrm{Hz}]}\end{array}$ \\
\hline $120 \mathrm{~mm}$ & 6.13 & 77.4 & 7.43 & 67.9 & 7.98 & 57.3 \\
\hline $140 \mathrm{~mm}$ & 4.65 & 57.3 & 5.63 & 49.1 & 6.08 & 42.1 \\
\hline $160 \mathrm{~mm}$ & 3.51 & 43.1 & 4.25 & 39.3 & 4.51 & 32.0 \\
\hline $180 \mathrm{~mm}$ & 2.72 & 34.3 & 3.31 & 29.6 & 3.47 & 25.3 \\
\hline
\end{tabular}

The mechanical behaviour of the composite materials may be influenced by the resin properties and their capacity to create a synergistic effect, together the reinforcing materials. The comparison of the trial results point out an important modification of the mechanical properties when changing the proportion between epoxy resin and natural resins.

\section{Conclusions}

We notice a decrease in the values of the tensile strength and the modulus of elasticity when increasing the natural resin volume proportion in the mixture. Although the mixtures with a larger amount of epoxy resin have higher mechanical properties, we cannot say that there is proportionality between the tensile strength, or the modulus of elasticity and the volume proportion of epoxy resin.

There are also changes in the characteristic curve forms. If, in the case of resins where the natural resin proportion is $60 \%$ and $70 \%$ respectively the characteristic curve is almost linear, in the case of 
resins where the natural resin is $80 \%$ there is an obvious nonlinearity of the characteristic curve, which appears from the very beginning of the stress, revealing a plastic behaviour.

Modifications also appear in the elongation at break, which augments when there is an increase in the natural resin proportion in the mixture. Therefore, an increase in the Dammar proportion brings about an increase in the ductility of the hybrid resins obtained. This can be used for controlling the mechanical properties of composite materials with Dammar-based bio-resin matrices.

As far as the vibration behaviour is concerned, we notice a rise of the damping capacity when the Dammar proportion is increased in the mixture.

Since the damping coefficient depends on the sample length we may calculate the loss factor $\eta$ (calculated by the ratio $\eta=\frac{\mu}{\pi v}$ given in [27], where $\mu$ and $v$ are the damping coefficient and the frequency, according to Table 2) for each of the studied resins. We obtain the following results:

- for the hybrid resin with $60 \%$ Dammar $\eta=0.0255$;

- for the hybrid resin with $70 \%$ Dammar $\eta=0.0353$;

- $\quad$ for the hybrid resin with $80 \%$ Dammar $\eta=0.0446$.

We see that the modification of the Dammar proportion in the hybrid resin leads to important variations of the mechanical properties. If, as far as the elastic and strength properties are concerned, the damping values fall, the damping values rise when there is an increase in the amount of Dammar. This behaviour can be used for making composite materials adjusted to the practical necessities.

Based on the experimental tests performed so far, we can say that these types of hybrid resin ensure a good adhesion to the reinforcement elements.

We will try to use these hybrid resins to make composite materials that we will use in:

- the field of civil and industrial constructions to making the formworks and parquet;

- the medical field to manufactured of some prostheses (for nasal pyramid, hip and elbow).

\section{References}

1. VOICU, A.D., HADAR, A., VLASCEANU, D., Rev. Chim., 70 (11), 2019, 4123.

2. DRĂGHICI, S., PETRESCU, H.A., JIGA, G., HADAR, A., TUDOSE, V., BUCUR, D.M., TUDOSE, D.I., Rev. Chim., 70 (12), 2019, 4470.

3. MALKAPURAM, R., KUMAR, V., YUVRAJ, S.N., J. Reinf. Plast. Compos., 28, 2008, p. 1169.

4. SHOGREN, R.L., PETROVIC, Z., LIU, Z.S., ERHAN, S.Z., J. Polym. Environ., 12, 2004, p. 173.

5. UYAMA, H., KUWABARA, M., TSUJIMOTO, T., KOBAYASHI, S., Biomacromolecules, 4, 2003, p. 211.

6. KANEHASHI, S., OYAGI, H., LU, R., MIYAKOSHI, T., Prog. Org. Coat., 77, 2010, p. 24.

7. ISHIMURA, T., LU, R., YAMASAKI, K., MIYAKOSHI, T., Prog. Org. Coat., 69, 2010, p. 12.

8. DRISKO, G.L., SANCHEZ, C., Eur. J. Inorg. Chem., 32, 2012, p. 5097.

9. ZIVKOVIC, I., PAVlOVIC, A., FRAGASSA, C., BRUGO, T., Compos. Part B: Eng., 111, 2017, p. 148.

10. FRAGASSA, C., PAVloviC, A., SANTUlli, C., Compos. Part B Eng., 137, 2018, p. 247.

11. AZEMARD, C., MENAGER, M., VIEILlESCAZES, C., Environ. Sci. Pollut. Res. Int., 24, no. 36, 2017, p. 27746.

12. KONONENKO, I., VIGUERIE, L., ROCHUT, S., WALTER, P., Environ. Sci. Pollut. Res. Int., 24, no. 3, 2017, p. 2160.

13. HIDAYAT, A.T., FARABI, K., HARNETI, D., MAHARANI, R., MAYANTI, T., SETIAWAN, A.S., SUPRATMAN, U., SHIONO, Y., Nat. Prod. Sci., 23, 2017, p. 291.

14. UKIYA, M., KIKUCHI, T., TOKUNDA, H., TABATA, K., KIMURA, Y., ARAI, T., EZAKI, Y., OSETO, O., SUZUKI, T., AKIHISA, T., Chem. Biodivers., 7, 2010, p. 1871.

15. ROMERO-NOGUERAM, J., MARTIN-SANCHEZ, I., LOPEZ-MIRAS, M.M., RAMOS-LOPEZ, J.M., BOLIVAR-GALIANO, F., Electron. J. Biotechnol., 13, 2010, p. 6. 
16. ZAKARIA, R., AHMAD, A.H., Am. J. Appl. Sci., 9, no. 6, 2012, p. 890.

17. ZAKARIA, R., AHMAD, A.H., IJAST, 42, 2012 , p. 33.

18. PETHE, A.M., JOSHI S.B., Int. J. Pharm. Sci. Res., 4, no. 7, 2013, p. 2761.

19. ASTM D3039, Standard Test Method for Tensile Properties of Polymer Matrix Composite Materials https://www.astm.org/Standards/D3039

20. KUMAR, N., SINGH, S.P., Materials \& Design, 30, no. 10, 2009, p. 4162.

21. ORBAN, F., 5-th International Workshop on Multi-Rate Processes and Hysteresis, J. Phys. Conf. Ser., 2011, p. 268.

22. SARLIN, E., LIU, Y., VIPPOLA, M., ZOGG, M., ERMANNI, P., VUORNIEN, J., LEPISTO, T., Compos. Struct., 94, 2012, p. 3327.

23. MIRITOIU, C.M., BOLCU, D., STANESCU, M.M., CIUCA, I., CORMOS, R., Mater. Plast., 49, no. 2, 2012, p. 118.

24. BOWYER, E.P., KRYLOV, V.V., Compos. Struct., 107, 2014, p. 406.

25. YANG, J., XIONG, J., MA, L., ZHANG, G., WANG, X., WU, L., Compos. Struct., 117, no. 1, 2014, p. 362.

26. VANWALlEGHEM, J., De BAERE, I., LOCCUFIER, M., Van PAEPEGEM, W., J. Sound Vib., 333, no. 6, 2014, p. 1596.

27. BURADA, C.O., MIRITOIU, C.M., STANESCU, M.M., BOLCU, D., Rev. Rom. Mater., 45, no. 3, 2015, p. 244.

Manuscript received: 23.03 .2020 